\title{
Towards Acquiring Teachers' Professional Qualification Based on Professional Standards: Perceptions, Expectations and Needs on the Application Process
}

\author{
Tiiu Leibur ${ }^{1, *}$, Katrin Saks ${ }^{1}\left[\right.$ and Irene-Angelica Chounta ${ }^{2}$ (]) \\ 1 Institute of Education, University of Tartu, 50103 Tartu, Estonia; Katrin.Saks@ut.ee \\ 2 Department of Computer Science and Applied Cognitive Science, University of Duisburg-Essen, \\ 47057 Duisburg, Germany; irene-angelica.chounta@uni-due.de \\ * Correspondence: tiiu.leibur@ut.ee
}

Citation: Leibur, T.; Saks, K.; Chounta, I.-A. Towards Acquiring Teachers' Professional Qualification Based on Professional Standards: Perceptions, Expectations and Needs on the Application Process. Educ. Sci. 2021, 11, 391. https://doi.org/ 10.3390/educsci11080391

Academic Editors: Beng Huat See and Rebecca Morris

Received: 29 May 2021

Accepted: 27 July 2021

Published: 30 July 2021

Publisher's Note: MDPI stays neutral with regard to jurisdictional claims in published maps and institutional affiliations.

Copyright: (c) 2021 by the authors. Licensee MDPI, Basel, Switzerland. This article is an open access article distributed under the terms and conditions of the Creative Commons Attribution (CC BY) license (https:// creativecommons.org/licenses/by/ $4.0 /)$.

\begin{abstract}
This paper presents the findings of a study into the application process of the professional standards (PS) qualification in Estonia, which is a standard used to identify the level of professionalism of a teacher. The study collected the views of active teachers who have applied for the PS and those of the assessors to understand the shortcomings in the application and the expectations for the application process. The main challenges identified are that teachers lack respective skills to adequately comprehend qualification requirements (unambiguous interpretation of PS) and the lack of evidence-based performance indicators (difficult to prove) and weak self-analysis skills; hence, the teacher needs assistance. The research found that teachers need collaborative support, motivation and constructive feedback on their professional development (PD), both from colleagues and at school and national levels. Based on this research, it can be said that teachers who have gone through the application process have gained greater self-confidence, value themselves as teachers and continue their in-service training.
\end{abstract}

Keywords: teacher professional development; professional standards; professional qualification

\section{Introduction}

The world around us is constantly changing, setting new challenges for members of society. Economic and technological changes in society add increasing responsibility to teachers' work, and teachers must be prepared to apply their pedagogical competencies as knowledge and skills in order to cope in a rapidly changing society. Economic change has led to the globalization of society, competition between schools and market orientation [1], which requires teachers to be responsible, rational and also competitive.

The so-called "new professionalism" of the era [2] presents new challenges for the teacher. The teacher's role has expanded, becoming a provider of knowledge, counsellor, supervisor, supporter, social worker, problem solver, etc. This has brought with it higher expectations of teacher professionalism. As teachers' work expands beyond the classroom, new emotional and intellectual demands are placed on them. Thus, the teacher must be collegial and collaborate with different target groups and focus on new forms of communication and collaboration [3] inside as well as outside the school [4].

There has been an increase in attention to the lifelong development of teachers throughout their careers [5]. As a result, there are many competing views and concepts on professionalism. The concept of professionalism has been approached differently over time.

In describing his stages, Hargreaves [6] was guided by the concept of professionalism, which is related to the status of the teaching profession in society. He [6] characterized professionalism through four stages: the pre-professional stage, the stage of the autonomous professional, the stage of the collegial professional and the stage of the post-professional or postmodern professional. In the period of pre-professionalism, the teaching was based 
on traditions and standardized curricula. The next era of autonomous professionalism was characterized by teachers' individualism, isolation and privacy. The period of collegial cooperation is characterized by educational reforms, i.e., the diversity of teaching methods, the increased role of the social worker and the increase in the number of learners with special needs. In the postmodern (or post-professionalist) era, the school has been heavily influenced by global economic competition and has reduced teachers' autonomy. Hoyle [7], on the other hand, defined professionalism as restricted (for the teacher teaching was an intuitive activity in a classroom environment that did not engage much broader professional reading or activities and was based mainly on experience) and extended professionalism (interpreted as a teacher's collegial activity seeking to improve the practice through reading and continuous professional development, later referred to as PD). Pratte and Rury [8] defined professionalism as a set of educational professional values. Eraut [9], Goodson and Hargreaves [3] and Evans [10] defined the concept of new professionalism, which includes performance standards, public accountability, lifelong PD of professionals, collaboration with colleagues and stakeholders and professional innovation where three interrelated concepts - knowledge, autonomy and responsibility-are considered to form the core. Sachs [11], on the other hand, described teacher professionalism as a collegial relationship and collaboration, while organizational professionalism is part of management professionalism that focuses on performance and accountability.

Holroyd [12] summed it up as "professionalism is not some social-scientific absolute, but a historically changing and socially constructed concept-in-use". Thus, professionalism has been studied for a long time, and the definitions differ in both content and purpose. Professionalism is not static but in constant change, caused by the era and national interest. It is closely related to education policy and the needs of the national educational system.

The current study is grounded in the concept of professionalism of Snoek et al. [13,14], which is related to the output-based and competency requirements of the modern education system, an important part of which is the implementation of professional standards (PS) in improving the quality of education (see Section 1.1). We explore how to support a teacher to become a professional in their field.

The PD of teachers is a major educational issue in many countries. Changes in society pose new challenges for schools. Teachers have a key role in the process of the implementation of the changes, which requires extended professionalism from them [15] and should ensure the quality of the education provided $[13,16]$. Thus, the professionalism and PD of teachers play an important role to ensure the quality of education [15].

One strategy for assuring the increase in professionalism is using professional standards (PS) and competency frameworks that focus on teacher training, certification, continuing PD, career advancement and performance evaluation [17]. PS are the national basis for developing the knowledge, skills and professionalism required of teachers [18]. However, PS alone do not provide a solution to problems in education [19]. Based on previous research, it has been found that more qualified teachers ensure better learning outcomes for students [20] and are particularly productive at the time of applying for a qualification [21]. According to Darling-Hammond [19], "professional standards are not magic" formulae that can solve various educational problems (outdated curricula, unequal distribution of resources and lack of social support for children), but they support teachers' self-development and PD, academic knowledge and professional knowledge and the ability to apply this knowledge ethically and appropriately [22]. PS-based self-analysis helps teachers to identify their strengths and weaknesses and also highlights the need for further training [23] and development. Hayes [24] argued that teachers should have an opportunity to contribute to the development of PS, albeit in collaboration with stakeholders in the education community. PS as one of the key concepts are explored in more detail below (see Section 1.3).

The PS for teachers have been in use in Estonia since 2005. The aim of the PS is to support teachers' pre-service and in-service training, assess teachers' competencies and support them in their continuous professional development throughout their career [25]. 
Although the university may reward the graduates of master's studies with the certificate of professional qualification (if they wish), our study focuses on working teachers who want to upgrade their qualifications (for more details, see Section 1.4). Professional qualification (PQ) is raised and a professional exam is held on the basis of PS (Section 1.4). However, applying for a PQ is not a regular practice for all teachers, and hence, this study seeks to identify teachers' lack of interest in going through the process of applying for the qualification. Although the impact of the PS on teacher quality [26,27] and support for professional development [21,26] has been studied, little is known about the expectations and needs of teachers in both the PS and the application process.

Previous research conducted in Estonia [25] has shown that the PS have a strong impact on teacher training, but the PS were not found to influence teacher careers and their PD. However, it was shown that in-service training increases teachers' self-esteem and professional autonomy, although applying for a qualification level is their free choice, i.e., it depends on teachers' own views, attitudes and intrinsic motivation [28]. We assume that the level of qualification acquired and the accompanying moral and material recognition will certainly help to reduce the turnover and attrition of teachers.

The goal of this research is to understand the shortcomings of the application process and the needs and expectations of those who apply. The authors of the paper also try to understand the reasons for teachers' low interest in applying for the qualification and to explore how to support teachers in their professional development and in the process of applying for a PQ. The present research defines PD as a process of systematic self-analysis of teachers' competencies and planning of self-improvement (continuous professional development) based on PS that ensures the overall quality of teaching [25]. As research has shown, the content of PS is relatively similar across countries. As professional standards have been developed in Estonia in cooperation with representatives of different communities, the sharing of experiences on the shortcomings of applying for a profession and implementing professional standards, as well as suggestions for improvement, will certainly be of interest to international readers as well. It would give others the opportunity to compare the success and performance of their professional standards and application process with the Estonian experience.

For our research purposes, we analyse the different stages of applying for the teaching profession, based on the currently operating PS and the process of applying for the qualification in Estonia, and highlight the aspects and proposals that need to be developed. Proceeding from the goal of the research the following research questions (RQs) were posed:

Research Question 1 (RQ1): What are the shortcomings perceived by the different target groups under the current criteria and the application process?

Research Question 2 (RQ2): What are the expectations and needs of different target groups for professional standards and professional application procedures?

\subsection{Theoretical Framework}

The concept of professionalism used in the work focuses on the expectations of today's competitive and knowledge-based society. This research is based on the concept of professionalism by Snoek et al. [13,14]. Consequently, the requirement of professionalism, i.e., responsibility for one's professional activity and quality, is the core of the concept. Strengthening professional responsibility is closely linked to teaching and learning, curriculum renewal, peer support and cooperation and PD. Professional teachers are not "service" providers. They monitor their PD and training needs in order to keep abreast of modern educational innovations and thus constantly improve their knowledge (professional, academic and technological), i.e., they are lifelong learners. It is also important to work with different target groups (colleagues, students, parents) and with different communities, supporting innovation and the application of new knowledge and skills. The development and improvement of PS is also an area of competency for joint community action. An 
important feature of professionalism is the ability to reflect and the ability to apply theoretical knowledge in practice. This concept forms a holistic approach to professionalism, which is based on lifelong professional learning and recognizes the development of an autonomous professional.

The definition of professionalism relies on professional autonomy, professional application and further PD, PS, academic knowledge consisting of formal or technical knowledge, lifelong learning, cooperation inside and outside the profession, responsibility for professional quality, use of an expanded knowledge base, developing research and supporting innovation and commitment. These criteria characterise the role of the teaching profession in knowledge-based competition, lifelong learning and the innovations that accompany it, as well as the responsibility for the results and quality of the work [13].

The research also draws on the European Qualifications Framework and the Estonian Qualifications Framework, derived from the teacher competency model [29] which allows the identification of a teacher's PD and the continuation of their career. The qualification framework is defined as a means to achieve a common understanding of quality and content [18]. In this research, standards are considered both as evaluation criteria for determining competencies and as criteria describing the recommended level of achievement [30].

\subsection{Professional Standards for Teachers}

The aim of PS is to support the quality of teaching and the quality of teachers and can be described in general as a broad set of descriptions that teachers can strive for but also specific, that is, clearer descriptions, allowing evaluators to evaluate teachers' work based on evaluation criteria [31]. The concept of the standards is to define the quality or the level of achievement, i.e., the measure of teachers' qualities against the requirements of the framework (comparative assessment). PS are also seen as a tool in competition and for ranking. At the same time, standards can serve as goals in striving for idealism, thus being a driving force in PD [32].

PS serve as a measurement tool for determining teachers' competency [30], makes teachers' work transparent, treats teachers' work as an agreed set of rules in teaching [33] (p. 13) and can be used to measure teachers' effectiveness [11]. PS can also be used to study teachers' professional behaviour, improve teachers' performance and develop alternatives, i.e., standards as a reference framework and basis for self-regulation [34]. PS also serve as a decision-making tool based on common understandings and values [35], i.e., it not only measures but also shows how evidence is gathered, the extent to which the standards are met and how PS are used to evaluate performance [36]. PS provide a structure that teachers can use to analyse their work. The standards create a common understanding of competencies, which in turn support collaboration between different target groups [37]. PS as a measurement tool in the professional assessment framework give an idea of the ideal teacher, which on the one hand, can be a driving force for the need for self-development. On the other hand, it can create uncertainty for teachers about the accuracy of their actions [38]. PS are also seen as a tool for improving teachers' reputation [39]. They play an important role in assessing teachers' PD, providing opportunities for certification and recognition [40]. It is very important to understand that PS alone do not determine the need for in-service teacher training [37] but rather display the combined effect of teacher self-analysis and PS. Self-assessment of the achievement or non-achievement of goals affects teachers' self-efficacy and decisions made. Self-assessment increases teachers' self-responsibility and develops their key skills in working life, i.e., being reflective, selfgoverning and independent [41]. This research looks at PS as an opportunity for PD for a teacher with the aim of improving their professional quality throughout their career [11] and as an opportunity to manage their own development.

In most countries, PS have been implemented with the aim of improving the quality of the education and school system [22]. Teacher qualification frameworks and PS provide an overview of expectations of a teacher's knowledge and skills at the national education 
policy level at different stages of a teacher's career [18]. Although the governments have a constitutional responsibility for ensuring the quality of education, this can only be realised through cooperation between the ministries, schools and teachers, recognizing the role and responsibility of everyone [42]. When setting PS, it is agreed how good is good enough, i.e., setting an acceptable level of performance for the purpose. For example, whether the teacher has reached a higher standard level [43].

Ingvarson and Kleinhenz pointed out [23] the fact that PS in different countries have common structural features and a similar process of converging [44]. That is, the PS are based on a common understanding of the competencies required of teachers. For example, Belgium, Estonia, the Netherlands and the United Kingdom have implemented specific competency frameworks (in the form of knowledge, skills and attitudes and value lists by subject areas) that differentiate between beginner and advanced teacher levels [45].

\subsection{Professional Standards and Their Implementation}

Based on the needs of educational policy, the PS are constantly evolving and changing, which should take place in cooperation with teachers and stakeholders in educational communities $[11,24]$. This evolvement is based on the development of society and expectations for the quality and work of the teacher, which are closely interrelated. When compiling PS, it is important to rely on logic and monitor the use of language to avoid overlaps and repetitions. PS must also be regularly adjusted in the light of research and professional knowledge [43].

Research on the career of European teachers [46] shows that competency frameworks are mainly used for teacher learning, for defining curricula and learning outcomes and as a reference framework for in-service teacher training. They are rarely used to support teachers' careers (through the transition to new levels), and teachers in about half of European countries have a career structure with no prospects for advancement at all [47].

PS may differ from country to country in terms of structure and description of objectives. In Australia, PS have been developed on a subject basis and teachers are required to be accredited at the basic level of professional competency, with the aim of encouraging teachers' PD. The goal of the PS is to improve the quality of teaching and their professional status [26]. In the UK, PS are compulsory and also linked to the salary. They describe competencies at five levels (from a qualified teacher to an advanced teacher). PS have also been developed in the USA, but they are used differently [27]. In the USA, PS are used to improve the quality of teaching and teachers by supporting teacher preparation, remuneration, certification and professional development [48]. PS are applied in teacher training programs in the countries that have adopted a standard-based approach, such as Australia, Canada, Chile, the United Kingdom, Germany, New Zealand, the Philippines, Scotland, Singapore, Thailand, the United States, etc. [43]. In Estonia, PS support the teachers' professional training throughout the pre-service training and career [25]. For the teaching profession, an eight-level qualification framework was developed in 2005 and implemented in 2008 [29]. The Estonian Qualifications Framework (EstQR) combines national curricula for general education, vocational training standards, higher education standard and PS [49].

Teachers who have already received a professional certificate feel more valued professionally [28], which may increase teachers' motivation to assess their PD and apply for a higher qualification. Thus, the PS are not "elite" standards but standards that all qualified teachers should be able to achieve, given their continuous professional development. Passing the assessment fulfils an important psychological function-it provides the teacher with a professional certificate based on the assessment of the quality of the applicant's practice by respected, knowledgeable and trained colleagues. Professional certification confirms that the teacher is able to meet higher PS [30]. 


\subsection{The Process of Applying for a Profession in Estonia}

PS for teachers, launched in Estonia in 2005, emphasize the teacher's role as a reflective practitioner and a lifelong learner with the aim of supporting a teacher throughout their teaching career [25]. In Estonia, PS support the teachers' professional training throughout the pre-service training and career [25]. For the teaching profession, an eight-level qualification framework was developed in 2005 and implemented in 2008. The original PS were one-tier standards and described competencies for every teacher without specifying their level in three areas: planning and managing the learning process (including setting up the learning environment, mentoring, analysing and assessing student development) and learning (interpersonal competencies), communication and collaboration skills to support student motivation and PD and self-analysis. This formulation did not allow peers to distinguish between novice and experienced teachers [25].

In Estonia, PS have been in constant development. In 2013, the Education Professional Council developed PS, formulating the standards on different levels. In cooperation with various parties (teachers, educational experts, etc.), new PS for teachers were prepared and approved. As an innovation, a description of a teacher's professional activity was introduced at three different levels: teacher-level 7, senior teacher-level 7 (1) and master teacher-level 8 [50]. The new PS describe the competencies of teachers in the areas of planning learning and teaching activities; designing the learning environment; supporting learning and development; reflection and professional self-development; coaching and mentoring; and research and development, plus recurrent competencies and optional competencies: teacher level 7-supporting pupils with SEN, level 7 (1) senior teacherleadership or teacher supervision and training; level 8 master teacher-either teacher supervision and training, development of methodology and learning materials or leadership (one option). The profession (higher qualification) can be applied for by all teachers who have a master's degree and work as a teacher.

The Vocational Committee (VC) is responsible for the development and updating of the PS, the procedure of awarding the qualification and resolving disputes related to it. Since 2014, it has been possible to apply for a qualification through the Teachers' Union. The Teachers' Union is a teachers' professional association with voluntary membership and institutional members and includes a number of teachers' subject associations. The focus of the Teachers' Union is on emphasizing the role of the teacher, representing and protecting the professional interests of teachers in Estonian society. For awarding certifications on $\mathrm{PQ}$, the Teachers' Union convenes a Vocational Assessment Committee (VAC), where teacher-practitioners with the highest (master teacher) qualifications (29 teachers) act as voluntary assessors.

At present, the application procedure for PQ consists of three interrelated steps (Figure 1):

At present, the system of applying for a PQ is based on the principle that the Vocational Assessment Committee (VAC) gives the applicant its assessment on the basis of the documentation submitted by the applicant and the interview conducted. The committee assesses the competency of the applicant based on the PS criteria and compliance with the performance indicators. The Vocational Committee (VC), consisting of representatives of educational associations and universities (10 people), approves the reasoned proposal of the VAC to issue the qualification or not. It is a multi-step process (Figure 1) accomplished by two different committees (Vocational Assessment Committee and Vocational Committee), with the common goal of providing an objective and transparent assessment of teacher competency and supporting teacher PD while providing constructive professional feedback. 


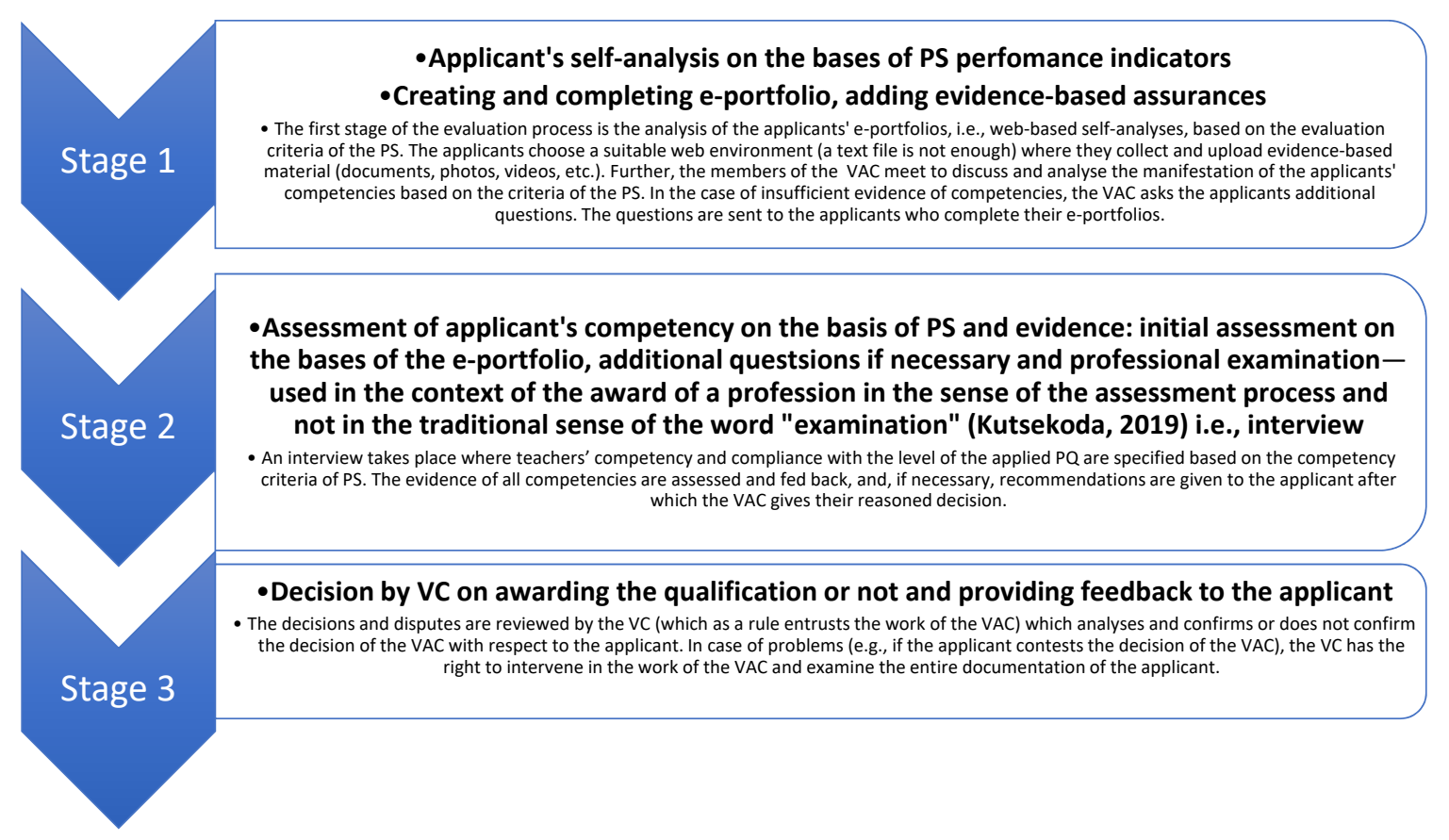

Figure 1. Process of professional application.

\section{Methods}

\subsection{Context and Participants}

In order to research the opinions and suggestions of the participants in the process (teachers who received the qualification, teachers who evaluated the applicants' suitability to the profession and one of the developers of PS), qualitative research was conducted. Qualitative analysis was found to be most suitable to investigate teachers' opinions and suggestions, providing the best opportunity to gather and understand their perceptions [51]. The phenomenological research method was used to gain an overview of the experience of applying for the qualification and to describe and interpret the universal nature of the interviewees' experience [52]. In order to obtain detailed, profound answers, semi-structured open-ended interviews were used [53]. Through open questions, teachers' attitudes and opinions were gathered in individual discussions while ensuring the coverage of shortcomings in PS and in the application process providing suggestions for their improvement.

Proceeding from the aim of the research to investigate the teacher applicants', assessors' and standards developer's perceptions of the PS and the application process, targeted sampling was used. The target group was selected based on their experience in applying for the qualification. The study focused on teachers who were employed and had experience in applying for the qualification. Applying for the professional qualification whilst in teacher training is a completely different process compared to that of already working teachers (not covered in this study). Thus, the target groups consisted of seven teachers, the inclusion criteria being:

- Working as a teacher;

- $\quad$ Being linked to the process of applying for qualifications (applicant, assessor, developer);

- Having acquired the teacher qualification.

The participants (Table 1) were all currently working teachers.

The PQ system for teachers is divided into four levels, i.e., level 6 (kindergarten teachers); level 7 (teacher) - a teaching profession that is lifelong and does not need renewal; and level 7 (1) (senior teacher) and the highest level 8 (master teacher)—also need to be renewed after every 5 years. 
Table 1. Background data of the participants.

\begin{tabular}{cccc}
\hline Participant & Gender & Professional Experience as a Teacher (in Years) & PQ Level \\
\hline T1 & F & 35 & Level 7 (1)* \\
T2 & F & 13 & Level 7 (1) \\
T3 & F & 40 & Level 8 \\
A1 & F & 43 & Level 8 \\
A2 & F & 15 & Level 8 \\
A3 & F & 45 & Level 8 \\
D & F & 15 & Level 8 \\
\hline
\end{tabular}

Notes: * (1)—senior teacher (level 7.1); T—teacher with qualification; A—assessor; D—developer.

The participants were reached through the Estonian Union of Teachers. They were the ones who were either in the process of applying for the qualification or the members of the assessment board. The sample size was small because since 2014 only 251 teachers out of 16,357 teachers, who work in schools in Estonia, have successfully obtained a PQ certificate (there are only about 160,000 general education school teachers in Estonia: about 14,000 women and 2000 men [54]). These figures are so small because of our small (teacher) population. Due to the small teacher population in Estonia, it was not possible to recruit more people who had recently been involved in the application process and had volunteered to participate in the study. The participants were first contacted via e-mail, and they were informed about the aim of the research and the background of the interviewer and asked for their consent to be interviewed. The individual interviews were conducted between May 2019 and July 2019.

\subsection{Data Collection}

For collecting data, individual semi-structured interviews were used. The focus of the research was on the criteria of PS. The interviews were conducted face-to-face at a time and place appropriate for the interviewees. The interview with one of the developers of PS took place via Skype because meeting in person was not possible due to the long distances and busy schedule. The interview questions were formulated proceeding from the research questions. The semi-structured design of the interview enabled us to go deeper and investigate the interviewees' perceptions in more detail. The interview questions were different for different target groups according to the role the person had in the process of applying for qualification (Table A1): 9 questions for the applicants, 9 for the assessors and 8 for the developer of PS. The questionnaire was compiled to investigate the interviewees' perceptions of the shortcomings in the current PS and the procedure of applying for them, i.e., RQ 1 (questions 1-5). The second part of questions, i.e., RQ 2 (questions 6-9), was to find out the expectations and needs of teachers with regard to PS and the procedure of applying for them. In order to improve the quality of the research tool and test the interview questions, a pilot interview was conducted with one of the teachers from the sample group. It became evident that the interviewee understood all questions and the interviewer managed to gather necessary information. As the prepared questions did not need changing, the data received from the pilot interview were included and analysed together with the data from other interviews. At the beginning of each interview, the interviewer introduced themselves and the aim of the research. The interviewees were informed of the confidentiality of the process and were asked for permission to audiorecord the interview. The shortest interview lasted $20 \mathrm{~min}$ and the longest $1 \mathrm{~h}$ and $15 \mathrm{~min}$.

\subsection{Data Analysis}

Qualitative inductive content analysis was used to analyse the data gathered. In the course of the data processing, we looked for similar patterns appearing in the collected data. This method enabled us to elicit thorough information and enabled the interviewees to substantiate their arguments. The interviews were fully transcribed, 37 pages in total. The shortest interview was 4 A4 pages long and the longest 13 A4 pages. Pseudonyms 
(Table 1) were used in the transcripts. The fragments of the recordings which could have revealed the identity of the interviewee were not transcribed.

For data analysis, QCAmap was used. This enabled us to code, store and organise the data. It also allowed the codes to be used repeatedly. The coding was based on RQ. In order to increase the reliability of the work, the coding was done repeatedly and the codes were checked by co-authors. The coding process provided 10 codes for the first research question divided into 7 subcategories which later were grouped into 5 main categories; 9 codes for the second research question resulted in 2 main categories. In the following section, the research results are presented with extracts from the transcription attached.

\section{Results}

The results of the data analysis are presented according to the research questions and described regarding sub- and main categories. The findings are illustrated with excerpts from the interviews, accompanied by the pseudonym of the interviewee.

Research Question 1 (RQ1): What are the shortcomings perceived by the different target groups under the current criteria and the application process?

The analysis of data revealed that there are shortcomings in five categories: perceptions of deficiencies while interpreting the PS, shortcomings in the first stage of application (e-portfolio and self-analysis), evidence-related shortcomings and shortcomings in the second stage of application (discussion/interview) and shortcomings in the third stage of application for PQ (Vocational Committee).

\subsection{Perceptions of Deficiencies While Interpreting the PS}

The interviews revealed a common understanding between assessors and applicants that teachers are not actually able to read PS and do not understand their content. This is where the description of the performance criteria of the PS is either incomprehensible or not sufficiently understood:

"And when I first applied, I realized that I still couldn't read the document. Look, here's the tricky bit that teachers stumble on. They cannot understand what the document actually says..." (T3)

“To be honest, it doesn't make it easy for a teacher-the language contains too much jargon" (A2)

All three target groups found the content of PS difficult to understand due to the complex wording $(A, C)$ and the large number of repetitions (T) of some of the criteria's performance indicators.

In addition, all target groups unanimously acknowledged that at the moment of applying for the qualification, the teachers are not able to explain the criteria to themselves, which leads to a significant deficiency in self-analysis. Teachers may be competent, based on PS criteria, but they are not aware of their own competency.

As a shortcoming, all target groups also noted the fact that although applicants have the right to choose the level within the profession they want to apply for, they lack the skills and abilities to assess themselves, even when relying on the performance criteria, thus often choosing the wrong level to aim at. Thus, it is difficult for the applicants to understand whether their competencies are sufficiently demonstrated against the requirements of PS.

Both the evaluators and the developer pointed out that all applicants have the freedom to apply for teacher level 7, which lasts until the end of their careers. This can lead to the situation where teachers are contented with level 7 as the process of applying for a higher $\mathrm{PQ}$ is labour-intensive and complex and only lasts 5 years.

"There have been cases in the application rounds where teachers who could actually apply for the profession of Master Teacher in their evidence and professional experience apply for Teacher Level 7 simply because they are not familiar 
enough with the awarding system, they apply for Teacher Level 7 because it is open-ended"... (D)

\subsection{Shortcomings in the First Stage of Application (e-Portfolio and Self-Analysis)}

The process of applying for the qualification at stage 1 consists of creating an eportfolio and self-analysis based on the performance indicators of PS. It is the task of the applicants to give a thorough overview of their competencies in the e-portfolio by including evidence-based documents. The assessors acquire the first impression of the competency of the applicants by reading the e-portfolio and finding evidence of the expected competencies for the performance indicators described in the PS.

As a shortcoming, the assessors and the developer jointly pointed out that it is certainly not possible to draw definitive conclusions about teachers' competencies from e-portfolios only because e-portfolios do not provide a complete overview of the applicants' competencies ("some teachers are not good writers, some teachers are able to write loads about nothing", A2).

In addition, reading and evaluating e-portfolios can be difficult for the assessor objectively because of the applicants' self-analysis, structuring, technical and self-expression skills:

“...e-portfolios are different, some are more scientific; others in essay form-which make it difficult to find the important points in them." (A1)

The need for the development of self-analysis skills emerged as a generic theme for all target groups:

"...so that applying teachers would be more capable of analysing their work and not rely on their gut feeling" (A3)

All target groups stressed that the ultimate goal should not be overlooked and that it is important for teachers to understand that a complete compliance of all competencies with PS is the ideal and almost impossible to achieve.

"Realistically, no one can achieve the maximum, it is not possible" (A1, A2, A3)

There is no systematic approach to what a teacher should do over a period of time (in-service training, etc.). Teachers are free to decide on their own development needs, and there are no direct demands from the state. As a result of that, teachers' development can be chaotic.

"We do not have an institution at the national level that sets out the directions or priorities we have in teaching or being a teacher that would bring all teachers to a particular level. The big downside to me is that there is no mechanism that works for all teachers to have at least some training in every 3 or 5 years, to become familiar with both SEN and digital..." (D)

There is also no national incentive system for teachers with higher qualifications in terms of salary, i.e., even if the teacher has level 8, their salary may stay the same. The salary increase depends primarily on the head of the school, their values and the budget of the school. Thus, there is no state institution in Estonia that would prioritise teachers with higher levels.

\subsection{Evidence-Related Shortcomings}

Evidence-based self-analysis is one of the requirements for applying for the qualification. The current system of applying for qualification is built on trust:

"It would be a trust-based system for teachers to regain confidence by analysing their activities and receiving support from other teachers, and feedback on the necessity and importance of their work." (D)

Both applicants and assessors pointed to the lack of the requirement for school evaluation, which can also be interpreted as a lack of interest and support from the school. Also highlighted as a shortcoming is the lack of a video lesson or the requirement for observing a 
lesson-teachers want to demonstrate their commitment in the teaching process. However, the following concern arises: filming can become a distraction, and this type of proof may not be suitable for students with special needs in the classroom. Teachers' poor IT skills—editing, publishing, etc.-are also hindering factors in creating video material. The eSafety aspect (i.e., netiquette-follow the rules of how to behave safely on the Internet to protect yourself and your devices) and the General Data Protection Regulation (GDPR), which requires parental permission to film their children and publish the film, also play a major role.

There was also confusion among applicants and assessors about guidance by and cooperation with universities, which is very difficult in practice. Research guidance the universities provide high school teachers with offers an outlet and an opportunity to collaborate with them, but it is a much bigger challenge for primary school teachers as universities offer fewer projects that would involve primary school students and teachers.

There may also be some problems with the evidence-based self-analysis in the eportfolio (not sufficient evidence or the evidence too general), but these are mostly compensated for in the next step of applying for the PQ.

\subsection{Shortcomings in the Second Stage of Application (Discussion/Interview)}

The second stage of the application process is the interview based on pre-completed documentation (self-analysis and e-portfolio) with the applicant. One shortcoming the applicants highlighted was the undefined structure of the interview, i.e., the applicants do not know what the particular VAC wants to hear and whether they prefer the scientific approach or the applicant's own views:

"Later, I realized that I was stuck in too much detail, I should have seen the bigger picture. I should have brought out scientifically sound or my own views, but I was just stuck in details..." (T3)

As with applicants, the content of the conversation is confusing for assessors as well; assessors expect the interview to complement and support the applicants' self-analysis:

“...this conversation should complement the applicant's self-analysis, that would be the ideal" (A2)

The developer of the PS highlighted the shortcomings in the joint discussions and training of the assessors, which again clearly indicates a lack of time and, to some extent, irresponsibility of the assessors. In addition, some of the shortcomings in the work of assessors can be due to the busy work schedules, namely, because they work as practising teachers.

"Everyone makes their own notes (A1), but they should be collected and reviewed together. Unfortunately, this is not always possible due to lack of time" (T3)

Hence there is a need for the assessors to find more time to cooperate and to write the unified opinion of the applicant's progress before sending off the feedback document and asking additional questions concerning the applicants' under-performance.

As a major shortcoming, the developer highlighted the quality of feedback provided by the assessors, which should support applicants' self-esteem and self-development needs, highlight the best performance and motivate applicants to develop further...

"It would be necessary to highlight those strengths and the specific competences that need to be developed from the point of view of the applicants so that they not only receive the analysis but also receive a meaningful assessment." (D)

High-quality feedback should include an assessment of the teacher's performance according to PS and recommendations for setting goals for further development 


\subsection{Shortcomings in the Third Stage of Application for Professional Qualification (Vocational Committee)}

The third stage of the assessment process is carried out by a Vocational Committee (VC) consisting of 10 people from different educational backgrounds. The committee shall approve or reject the decisions of the VAC. The work of the VC is based on the feedback and suggestions of the VAC, i.e., the VC trusts and accepts the decisions of the VAC. As a shortcoming, the developer once again pointed out the limited time resource for commission meetings.

Research Question 2 (RQ2): What are the expectations and needs of different target groups for professional standards and professional application procedures?

The analysis of the data revealed two main categories: expectations and needs for the first stage of the application process and expectations and needs for the second stage of the application process.

The application procedure for professional qualification consists of three interrelated steps: e-portfolio and self-analysis; professional examination-used in the context of the award of a profession in the sense of the assessment process and not in the traditional sense of the word "examination" [50], i.e., interview; and decision by Vocational Committee on awarding the qualification.

\subsection{Expectations and Needs for the First Stage of the Application Process}

All three target groups found that creating an e-portfolio is a long, time-consuming and complex process that requires the teachers to stretch themselves. Teachers are expected to determine the structure of their e-portfolio and compile their self-analysis based on PS and their work experience:

"The teacher's own experience is what is most important, theory is to confirm this. Not that you have a lot of theory and two sentences about yourself." (A3)

The common understanding of all target groups was that teachers' self-analysis skills need to be developed. The target groups expected that a video lesson or lesson observation could be used in the qualification application process for assessors to familiarise themselves with the teacher's work and for the teacher to improve their self-analysis skills. A video lesson or lesson observation provides an insight into the teacher's work and is evidence-based.

“... video lesson should be recorded or a member of the committee would come to watch your lesson or talk to you beforehand. I imagine that it would help a lot in terms of self-analysis." (T1)

All target groups expected that the teacher could upload the recorded video lesson in their e-portfolios in clips, followed by the analysis of the successful and unsuccessful parts of their work:

“It doesn't have to be a 45-min video, it could be one chosen clip I might like and another where I feel like I've failed as a teacher. It could be inside in the e-portfolio because it makes you analyse yourself. Otherwise, this self-analysis would remain very superficial." (T3)

All target groups found that teaching is not only the individual work of the teacher but collaboration with colleagues and management, and thus it is important that the head of the school assesses the teacher.

“...as the teacher's professionalism does not only come from teaching, it is also thanks to cooperation with..." (A1)

In conclusion, it can be said that the purpose of all the above-mentioned activities is to provide an objective overview of a teacher applying for a profession, that is, an overview of their professionalism. At the same time, they are expected to supplement this overview with evidence-based videos, pictures and various references (from the employer, community of practice, etc.). 


\subsection{Expectations and Needs for the Second Stage of the Application Process}

The most important thing in an interview is the direct communication with the applicant. Before the interview, the assessors examine the applicant's written self-analysis, but the interview is the part of the process that ensures direct contact. Assessors expect the interview to reveal the applicant's personality traits and provide a more thorough overview of the applicant's professionalism and competencies:

"...Face-to-face with the applicant to assure that everything in their digital portfolio and everything they have provided in answer to our supplementary questions is very good; that they are doing a good and necessary job and they do not have to underestimate themselves, even if they may not have the school feedback on their work, which can occasionally happen..." (A2)

The interview gives the assessors the opportunity to specify and talk about the shortcomings in their self-analysis and confirms the manifestation of competencies in their reflection:

"... the need to indicate those competencies that are scarce or would like to be questioned and clarified..." (A3)

All target groups expected the interview to become a discussion between colleagues, which is a supportive system for applicants but also supports the PD of assessors. If some competencies are questionable, additional pre-interview questions would help to clarify the applicant's competencies.

Both assessors and developers believed that it is the task of the VAC to conduct the interview so that teachers feel that the committee has worked through the documents they have submitted and that the committee emphasizes the more outstanding aspects of the candidates and recommends the development of less evident competencies.

"So that this were not just a statement of what this teacher is doing, but this conversation would really highlight the strengths of the teachers and the points that need improvement. So, it would not be just another self-analysis but also an assessment of the activities they really excel at." (D)

Currently, the procedure of conducting interviews differs from committee to committee:

"We have some basic questions we ask during the interview. Training sessions have also been organized on the topics of the interview. There could be more training, as the committees now have very different working arrangements. The basic issues of the conversations could also be standardized..." (A2)

The applicants emphasized that, in order to avoid confusion, more detailed information was needed on the content of the expected interview and on what the committee expected of them during the interview. Consequently, harmonization of the content of the interview would be necessary for both applicants and assessors (the common basis for the interview). Thus, all target groups expected that applying for a profession is a process in which the applicants receive constructive and supportive feedback.

\section{Discussion}

The main value of the work is identifying the assessments, needs and expectations given by the teachers to the qualification application process in order to make it more understandable to them. Previously identified weaknesses prevented teachers from understanding the content and performance of PS. From the results of this study, it is possible to pay attention to the shortcomings that emerged based on the expectations and needs expressed by the participants in the process of applying for the qualification. The practical value is getting an overview of teachers' perceptions of PS as a tool for assessing the professionalism of teachers when applying for a PQ by analysing the results of the research and finding an explanation why the PS of teachers are not being sufficiently used in Estonia. The following are the main shortcomings, needs and expectations relevant to the application process and PS (Table 2): 
Table 2. Findings per target groups.

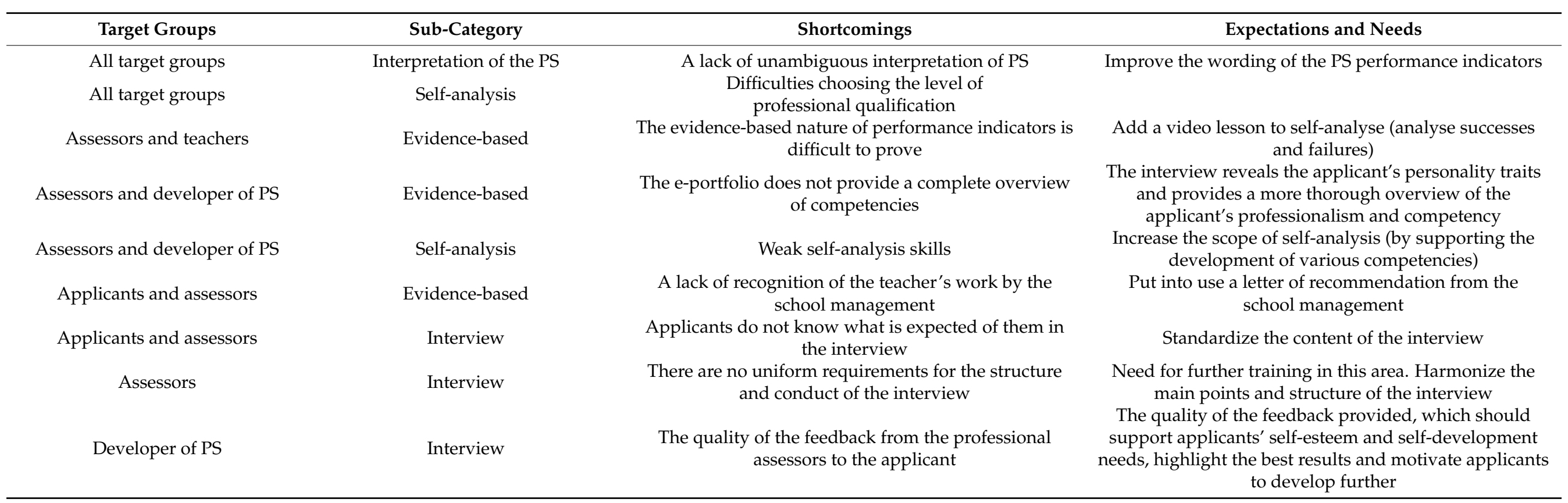


The shortcomings identified by all three target groups were: difficulties in choosing the level of professional qualification, the lack of unambiguous interpretation of PS, the lack of evidence-based performance indicators (difficult to prove) and weak self-analysis skills. The interviews revealed the reasons for the weak self-analysis, which highlighted the existence of a short time limit by the target groups and the fact that the teaching process is taken for granted and is not documented. It was also stated that teachers cannot write a self-analysis (either they are poor writers or they have weak analysis skills). Teachers tend to perceive self-analysis as self-praise and not as an analysis of one's strengths and weaknesses. It was also revealed that teachers can point out their weaknesses but cannot help them. Assessors stated that the teachers are not very confident, rather they are too self-critical, which in turn indicates a lack of recognition of the teacher's work by the school management (pointed out by applicants). The e-portfolio, however, does not provide a complete overview of the teacher's competencies (PS are compiled based on the ideal teacher), but it is the material on which the applicant is first assessed and additionally questioned. An important part of the research was the expectations and needs of the three target groups for the PS and the application process. The main expectation of all target groups turned out to be the improvement of the wording of the PS performance indicators. It was also considered necessary to introduce the four different levels of PQ; bring in a video lesson as a tool for self-analysis and evidence-based validation, which also supports the development of digital competencies; and put into use a letter of reference from the school management, which means that the management is aware and supports the teacher's willingness to apply for the PQ.

PS are constantly being developed with the aim of making the application process better and more efficient. In the Estonian context, the interest of teachers in applying for a PQ has increased year by year, but PS can only be applied on a voluntary basis at the level of both teachers and schools, which is probably the reason for the lack of interest.

All target groups accepted the current application procedure. On the one hand, their expectations and needs for improvement increase the scope of self-analysis by supporting the development of various competencies. On the other hand, it makes it easier for assessors to assess applicants' capabilities more effectively.

\section{Conclusions}

This research was based on the opinions and suggestions of three different target groups (teachers who applied for the profession, professional assessors and the developer) regarding the process of applying for a PQ following the requirements of the PS currently valid in Estonia. The main value of the work is identifying the shortcomings, needs and expectations teachers have found while applying for PQ in order to make the process more understandable for them. Previously, the identified weaknesses prevented teachers from understanding the content and performance of PS. Based on the results of this study, it is possible to eliminate the shortcomings based on the expectations and needs expressed by the participants in the process of applying for qualification. Another valuable outcome is getting an overview of teachers' perceptions of PS as a tool for assessing the professionalism of teachers when applying for a PQ. A valuable result is also the consensus on the shortcomings and needs of teachers' professional standards and on proposals to improve the application process for the profession, which, in cooperation with the Teachers' Union, will allow for further improvements.

As the application process for the PQ in Estonia was started as early as in 2014, the re-application process is already underway, which is a new development and requires another review of the PS. Currently, teachers who are seeking higher qualifications are the more skilled active professionals who are open to continuous self-improvement and educational and technological innovation. Their expectations and needs for improvement increase the scope of self-analysis by supporting the development of various competencies. Furthermore, it enables the assessors to assess applicants' capabilities more effectively. In summary, it can be said that raising the qualification of a teacher and thereby defining 
one's professional competencies is a free choice for a teacher, which largely depends on the teacher's internal motivation and self-improvement needs. Although this may vary from country to country, improving the qualifications of teachers is a national policy interest everywhere, assuring the professionalism of working teachers and the quality of education in the long term.

This study does not reflect differences in the application process or the objectives of using professional standards across countries. However, it provides insight and benchmarks on the application process and the functioning of professional standards for teachers in different countries. The study showed that teachers need collaborative support, motivation and constructive feedback on their professional development, both from colleagues and at school and national levels. Applying for a PQ is based on an overview, analysis and evidence-based professional activity of a teacher, which forms an important part of a teacher's PD. One of the reasons for the low level of teachers' application for PQ can be the insufficient professional recognition of teachers, which would certainly motivate teachers to apply for a higher PQ level. Currently, teachers who are seeking higher qualifications are the more skilled active professionals who are open to continuous self-improvement and educational and technological innovation. Teachers who have gone through the application process have gained greater self-confidence, value themselves as teachers and continue their in-service training. Therefore, the ones who passed the PS interviews are qualified teachers and are specialists in their field who are able to ensure quality teaching based on their personality.

Further research will focus on creating a learning analytical model which would help teachers in the process of applying for PQ.

\section{Limitations and Implications for Further Research}

This work focused on the target group whose members have already applied for the profession and have a higher level of PQ. One of the limitations of the study is that it was based on only working teachers who were upgrading their qualification and excluded those who were still learning to be teachers. The study considered only the views of those who had applied for the PS qualification. We acknowledged that this is a limitation of our sampling strategy. Future research should also include active teachers who have not applied for a qualification as well as those training to be teachers to understand the barriers or hesitancy in applying for the PS qualification. Another limitation is the extremely small sample consisting of only three teachers and three assessors. The findings of the study can therefore only be a snapshot view of these individuals and not necessarily the views of the majority. Nevertheless, their views highlight the challenges involved in the application process. In this case, it would be possible to investigate more precisely, on the one hand, the needs and expectations of teachers regarding the application process and requirements of the profession and, on the other hand, the direction in which the standards of the teaching profession are changing with the development of society. We also highlight the need for involving novice teachers, hoping to expand and repeat our study in the future.

There were cases where teachers had not been awarded the qualification they were applying for (but only professionals applying for the highest qualification were involved).

Author Contributions: Author Contributions: Conceptualization, T.L. and K.S.; methodology, T.L., K.S. and I.-A.C.; valida-tion, T.L., K.S. and I.-A.C.; formal analysis, T.L., K.S. and I.-A.C.; investigation, T.L., K.S. and I.-A.C.; data curation, T.L., K.S. and I.-A.C.; writing-original draft preparation, T.L.; writing-review and editing, T.L., K.S. and I.-A.C.; visualization, T.L.; supervision, K.S. and I.-A.C. All authors have read and agreed to the published version of the manuscript.

Funding: This research received no external funding.

Institutional Review Board Statement: Ethical review and approval were waived for this study, as it involved only adults who all gave informed consent for participation. No sensitive personal data were used in the study.

Informed Consent Statement: Informed consent was obtained from all subjects involved in the study. 
Data Availability Statement: Not applicable.

Conflicts of Interest: The authors declare no conflict of interest.

\section{Appendix A}

Table A1. Interview plan.

\begin{tabular}{|c|c|c|c|}
\hline \multirow[t]{3}{*}{ Research Questions } & \multicolumn{3}{|c|}{ Interview Questions } \\
\hline & \multicolumn{3}{|c|}{ Target Groups } \\
\hline & $\begin{array}{l}\text { Applicant for the } \\
\text { Qualification }\end{array}$ & Professional Assessor & $\begin{array}{c}\text { Developer of Professional } \\
\text { Standards }\end{array}$ \\
\hline $\begin{array}{l}\text { 1. How do target groups } \\
\text { perceive shortcomings in } \\
\text { current PS and professional } \\
\text { application procedures? }\end{array}$ & $\begin{array}{l}\text { 1. Prior information on } \\
\text { applying for a profession? } \\
\text { 2. Overview of evaluation } \\
\text { criteria (excessive, missing)? } \\
\text { 3. Disagreements during the } \\
\text { evaluation interview? } \\
\text { 4. Process evaluation, } \\
\text { suggestions? } \\
\text { 5. Satisfaction/non- } \\
\text { satisfaction with the invitation } \\
\text { application process? }\end{array}$ & $\begin{array}{l}\text { 1. Teacher's ability to choose a } \\
\text { professional standard? } \\
\text { 2. The most difficult criteria } \\
\text { for a teacher's } \\
\text { self-assessment? } \\
\text { Reason? } \\
\text { 3. Is an overview of the } \\
\text { teacher level sufficient? } \\
\text { 4. Shortcomings in analysing } \\
\text { e-portfolios? The solution? } \\
\text { 5. Shortcomings in the } \\
\text { conversation? The solution? } \\
\text { Disagreements in the } \\
\text { assessment? Solutions? }\end{array}$ & $\begin{array}{l}\text { 1. Is a self-assessment } \\
\text { overview of the teacher's level } \\
\text { sufficient? } \\
\text { 2. How does the (initial } \\
\text { evaluations) work? } \\
\text { 3. Shortcomings in the 's } \\
\text { work? } \\
\text { 4. Shortcomings in the work } \\
\text { of the professional committee? } \\
\text { 5. How does the work? Initial } \\
\text { assessments of documents? } \\
\text { 6. Disagreements in the } \\
\text { evaluation (have there been } \\
\text { any reasons for reaching } \\
\text { solutions?) }\end{array}$ \\
\hline $\begin{array}{l}\text { 2. What are the expectations } \\
\text { and needs of the target groups } \\
\text { for the current professional } \\
\text { standards and the procedure } \\
\text { for applying for the } \\
\text { qualification }\end{array}$ & $\begin{array}{l}\text { 6. Documentation and overlap } \\
\text { of conversation goals? } \\
\text { 7. Proposals for professional } \\
\text { standards and the } \\
\text { professional application } \\
\text { process } \\
\text { 8. The purpose of the } \\
\text { interview, was it based on } \\
\text { evaluation criteria and } \\
\text { documentation? } \\
\text { 9. Assessment of the } \\
\text { invitation application process }\end{array}$ & $\begin{array}{l}\text { 7. Overlap of documentation } \\
\text { and conversation goals? } \\
\text { 8. The purpose of the } \\
\text { conversation/interview? } \\
\text { 9. Assessment of professional } \\
\text { standards and the application } \\
\text { process? }\end{array}$ & $\begin{array}{l}\text { 7. Prerequisites for applying } \\
\text { as a teacher? } \\
\text { 8. How and on what } \\
\text { documentation does the } \\
\text { Vocational Committee work } \\
\text { (final stage) }\end{array}$ \\
\hline
\end{tabular}

\section{References}

1. Gewirtz, S.; Mahony, P. Changing Teacher Professionalism: International Trends, Challenges and Ways Forward, 1st ed.; Hextall, I., Cribb, A., Eds.; Taylor Francis Group: Abingdon, UK; Routledge: London, UK, 2007; pp. 19-30.

2. Hargreaves, A. Four Ages of Professionalism and Professional Learning. Teach. Teach. 2000, 6, 151-182. [CrossRef]

3. Hargreaves, A.; Goodson, I. Teacher's Professional Lives: Aspirations and Actualities. In Teacher's Professional Lives; Goodson, F., Hargreaves, A., Eds.; Falmer Press: London, UK, 1996; pp. 1-27.

4. Whitty, G. Changing modes of teacher professionalism: Traditional, managerial, collaborative and democratic. In Exploring Professionalism; Cunningham, B., Ed.; Institute of Education, University of London: London, UK, 2008; pp. $28-49$.

5. European Council. Available online: https:/ / eur-lex.europa.eu/LexUriServ/LexUriServ.do?uri=OJ:C:2009:302:0006:0009:EN:PDF (accessed on 10 November 2020).

6. Hargreaves, A. Four ages of professionalism and professional learning. In Education, Globalization, and Social Change; Lauder, H., Brown, B., Dillabough, J.-A., Halsey, H., Eds.; Oxford University Press: Oxford, UK; New York, NY, USA, 2006 ; pp. 672-691.

7. Hoyle, E. Professionality, professionalism and control in teaching. Lond. Educ. Rev. 1974, 3, 13-19.

8. Pratte, R.; Rury, J.L. Teachers, Professionalism, and Craft. Teach. Coll. Rec. 1991, 93, 59-72.

9. Eraut, M. Developing Professional Knowledge and Competence; Falmer Press: London, UK, 1994.

10. Evans, L. Professionalism, professionality and the development of education professionals. Br. J. Educ. Stud. 2008, 56, 20-38. [CrossRef]

11. Sachs, J. Professional standards: Quality teachers for the future. In Proceedings of the Sharing Experience: Ways forward on Standards Conference, Melbourne, Australia, 21-22 August 2005. 
12. Holroyd, C. Are assessors professional? In Active Learning in Higher Education, 1st ed.; Open University Press: Buckingham, UK, 2000; Volume 1, pp. 13-19.

13. Theories on and Concepts of Professionalism of Teachers and Their Consequences for the Curriculum in Teacher Education. Available online: http:/ / theories-on-and-concepts-of-professionalism-hugarian-publication.pdf (accessed on 12 November 2020).

14. Snoek, M.; Swennen, A.; Van der Klink, M. The teacher educator: A neglected factor in the contemporary debate on teacher education. In Proceedings of the 3rd Annual Conference on Teacher Education Policy in Europe (TEPE), Umea, Sweden, 18-20 May 2009. Available online: https:/ / www.amsterdamuas.com/binaries/content/assets/subsites/kc-oo/publicaties/theteacher-educator-a-neglected-factor-in-the-contemporary-debate-on-teacher-education.pdf (accessed on 10 October 2020).

15. Hoyle, E. Changing Conceptions of Teaching as a Profession: Personal Reflections. In Teaching: Professionalization, Development and Leadership; Johnson, D., Maclean, R., Eds.; Springer: Dordrecht, The Netherlands, 2008; pp. 285-304.

16. Kleinhenz, E.; Ingvarson, I. Standards for Teaching: Theoretical Underpinnings and Application. 2007. Available online: https:// www.researchgate.net/publication/43328197_Standards_for_Teaching_Theoretical_Underpinnings_and_Applications (accessed on 15 September 2020).

17. OECD Library Teachers Matter: Attracting, Developing and Retaining Effective Teachers. Available online: https://www.oecdilibrary.org/education/teachers-matter-attracting-developing-and-retaining-effective-teachers_9789264018044-en (accessed on 8 November 2020).

18. Guerriero, S.; Toledo-Figueroa, D.; Révai, D. Teacher professionalism and knowledge in qualifications frameworks and professional standards. In Pedagogical Knowledge and the Changing Nature of the Teaching Profession; Guerriero, S., Ed.; OECD Publishing: Paris, France, 2017; pp. 73-91.

19. Darling-Hammond, L. Reshaping Teaching Policy, Preparation, and Practice. In Influences of the National Board for Professional Teaching Standards; AACTE Publications: Washington, DC, USA, 1999; pp. 5-39.

20. Hattie, J. Teachers Make a Difference, What Is the Research Evidence? Available online: https://www.researchgate.net/ publication/252090858 (accessed on 12 October 2020).

21. Bourke, T.; Rayan, M.; Ould, P. How do teacher educators use professional standards in their practice? Teach. Teach. Educ. 2018, 75, 83-92. [CrossRef]

22. Standards Frameworks for Teachers and School Leaders. Available online: https://www.academia.edu/8238247/Standards_ Framework_for_Teachers_and_School_Leaders (accessed on 10 November 2020).

23. Ingvarson, L.; Kleinhenz, E. A Review of Standards of Practice for Beginning Teaching. 2003. Available online: https: //www.researchgate.net/publication/43328189_A_review_of_standards_of_practice_for_beginning_teaching (accessed on 10 November 2020).

24. Hayes, T. Professional teaching associations and professional standards: Embedding standards in the discourse of the profession. Teach. Aust. 2006. Available online: https://apo.org.au/node/1897 (accessed on 10 September 2020).

25. Pedaste, M.; Leijen, Ä.; Poom-Valickis, K.; Eisenschmidt, E. Teacher professional standards to support teacher quality and learning in Estonia. Eur. J. Educ. 2019, 54, 389-399. [CrossRef]

26. Mayer, D.; Mitchell, J.; Macdonald, D.; Bell, R. Abbreviated Professional standards for teachers: A case study of professional learning. Asia Pac. J. Teach. Educ. 2005, 33, 159-179. [CrossRef]

27. Mars, E. Professional standards, teacher careers and the conference enactment of professional judgement: An exploration of the discourses. In AARE 2012 Conference Proceedings, Proceedings of the Joint Australian Association for Research in Education and Asia-Pacific Educational Research Association Conference, Sydney, Australia, 2-6 December 2012; Australian Association for Research in Education (AARE): Canberra, Australia, 2012.

28. Leibur, T.; Saks, K.; Chounta, A.E. Teachers' and Assessors' Perceptions of the Application Process of Professional Qualification. In Proceedings of the INTED 2020, Valencia, Spain, 2-4 March 2020.

29. Estonian Qualifications Framework (EstQR). Available online: https://www.kutsekoda.ee/en/estonian-qualificationsframework-estqf/ (accessed on 1 October 2020).

30. Ingvarson, L. Development of a National Standards Framework for the Teaching Profession. ACER Policy Briefs. Issue 1; ACER Press: Camberwell, Australia, 2002; pp. 3-32.

31. Professional Standards for Teachers and Teacher Education: Avoiding the Pitfalls. Available online: https://img.scoop.co.nz/ media/pdfs/0604/avoiding_pitfalls.pdf (accessed on 12 October 2020).

32. Cumming, J. The Push for Standards in Teaching Profession: Stakeholders, Strategies and Scenarious; Australian College of Educator: Camberwell, Australia, 2010; pp. 1-14.

33. Bowker, G.; Star, S.L. Sorting Things out: Classification and Its Consequences, 2nd ed.; The MIT Press, Massachusetts Institute of Technology: Cambridge, MA, USA, 1999; pp. 1-34.

34. Koster, B.; Dengerink, J.J. Professional standards for teacher educators: How to deal with complexity, ownership and function. Experiences from the Netherlands. Eur. J. Teach. Educ. 2008, 31, 135-149. [CrossRef]

35. Sykes, G.; Plastrik, P. Standard Setting as Educational Reform; American Association of Colleges for Teachers of Education: Washington, DC, USA, 1993; pp. 15-45.

36. Ingvarson, L.C.; Hattie, J. Assessing teachers for professional certification: The first decade of the National Board for Professional Teaching Standards. In Advances in Program Evaluation; Ingvarson, L.C., Hattie, J., Eds.; Emerald Group Publishing Limited: Bingley, UK, 2008; Volume 11, pp. 55-93. 
37. Kriewaldt, J. Research into relationships between teacher professional learning and teaching standards. In Proceedings of Conference of the Australian Association for Research in Education, Proceedings of the AARE 2008 International Educational Education Research Conference, Brisbane, Australia, 30 November-4 December 2008; Jeffrey, P.L., Ed.; Papers collection; Association for Research in Education: Melbourne, Australian, 2008.

38. Ball, S. Performativities and fabrications in the education economy: Towards the performative Society? Aust. Educ. Res. 2000, 27, 1-23. [CrossRef]

39. Sachs, J. Teacher professional standards: Controlling or developing teaching? Teach. Teach. 2003, 9, 175-186. [CrossRef]

40. Ingvarson, L.C. Recognising accomplished teachers in Australia: Where have we been? Where are we heading? Aust. J. Educ. 2010, 54, 46-71. [CrossRef]

41. Sadler, D.R. Interpretations of criteria-based assessment and grading in higher education. Assess. Eval. High. Educ. 2005, 30, 175-194. [CrossRef]

42. Snoek, M. The teaching profession in the Netherlands: From regulative structures to collaborative cultures. In The Dutch Way in Education: Teach \& Lead the Dutch Way; Heijmans, J., Christians, J., Eds.; Onderwijs Maak Je Samen: Helmond, The Netherlands, 2017; Volume 3, pp. 91-107.

43. Standards for Graduation and Initial Teacher Certification: The International Experience. Available online: https: / works.bepress. com/lawrence_ingvarson1/206/ (accessed on 27 September 2020).

44. Guerriero, S.; Toledo-Figueroa, D.; Révai, D. Teacher' Pedagogical Knowledge: What it is and how it functions. In Pedagogical Knowledge and the Changing Nature of the Teaching Profession; Guerriero, S., Ed.; OECD Publishing: Paris, France, 2017; pp. 99-115.

45. Caena, F. Teacher Competence Frameworks in Europe: Policy-as-discourse and policy-as-practice. In The Changing Role of Teachers; Wiley Online Library: Hoboken, NJ, USA, 2014; Volume 49, pp. 311-331.

46. Teaching Careers in Europe: Access, Progression and Support. Available online: https://op.europa.eu/en/publication-detail/-/ publication/9ef5c37e-1b75-11e8-ac73-01aa75ed71a1/language-en/format-PDF/source-search (accessed on 23 October 2020).

47. Snoek, M.; Dengerink, J.; De Wit, B. Reframing the teacher profession as a dynamic multifaceted profession: A wider perspective on teacher quality and teacher competence frameworks. Abbreviated Eur. J. Educ. 2019, 54, 413-425. [CrossRef]

48. Gerstner, L.; Ackerman, A.; Barnes, R.; Beattie, R.; Chenault, K.; Condit, D. Teaching at Risk: Progress and Potholes; The Teaching Comission: New York, NY, USA, 2006.

49. Estonian Qualifications Authority. Available online: https://www.kutsekoda.ee/en/ (accessed on 1 October 2020).

50. Kutsestandardi Rakendamine Õpetajaks Kujunemisel ja Edasises Professionaalses Arengus. Available online: https://lytorn.files. wordpress.com/2016/10/kutsestandardi-rakendamine-ja-eneseanalc3bcc3bcs.pdf (accessed on 15 March 2020).

51. Robson, C. Real World Research, 2rd ed.; Blackwell Publishing: Malden, MA, USA, 2002.

52. Van Manen, M. Researching Lived Experience: Human Science for an Action Sensitive Pedagogy; State University of New York Press: Albany, NY, USA, 1990.

53. Turner, D.W. Qualitative interview design: A guide for novice investigators. Qual. Rep. 2010, 15, 754-760.

54. Stationary General Education. Available online: http:/ / andmebaas.stat.ee/Index.aspx?lang=en\&SubSessionId=48144bb2-6a504d7d-8fec-be8871a3e3ab\&themetreeid=6 (accessed on 19 July 2021). 